\title{
Lecturas de la Independencia en el exilio español del 39. José Gaos, Joaquín Xirau y Eduardo Nicol
}

\author{
Antolín Sánchez Cuervo
}

$\mathrm{I}$

\section{ntroducción}

Las independencias iberoamericanas no pasaron desapercibidas al pensamiento exiliado español del 39, aun cuando las lecturas que en este contexto se hicieron de ellas fueran más bien puntuales. Si nos centramos en el contexto mexicano, encontramos referencias a esta cuestión en las obras de José Gaos, Joaquín Xirau y Eduardo Nicol. El primero dedicó al pensamiento de la Independencia buena parte de su ensayo El pensamiento hispanoamericano (1944) y de la "Introducción" a su Antología del pensamiento de lengua española en la edad contemporánea (1945). ${ }^{1}$ En esta última figuran de hecho autores tan ligados a la experiencia emancipadora como Simón Bolívar, Andrés Bello, Domingo F. Sarmiento, Juan B. Alberdi y José Martí -y en definitiva, todos los que conforman la antología, de acuerdo con la amplísima significación filosófica que Gaos otorgará a dicha experiencia. De manera más fragmentada, aunque profusa, también hay que tener en cuenta la primera parte de su libro Pensamiento de lengua española (1945), titulada "El pensamiento hispano-americano. Notas para una interpretación histórico-filosófica". ${ }^{2}$ Las referencias de Xirau son contemporáneas a las de Gaos, aunque mucho más escuetas y puntuales, encontrándose en sus dos ensayos "Humanismo español (ensayo de interpretación)" (1942) e "Integración política de Iberoamérica" (1945). ${ }^{3}$ Nicol dedicó a la significación filosófica de la Independencia amplios comentarios en El problema de la filosofía hispánica (1961).

${ }^{1} \mathrm{Cf}$. José Gaos, Obras completas. V. El pensamiento hispanoamericano. Antología del pensamiento de lengua española en la edad contemporánea. Pról. de Elsa Cecilia Frost. México, unam, 1993, pp. 25-103.

${ }^{2}$ Cf. J. Gaos, Obras completas. VI. Pensamiento de lengua española. Pensamiento español. Pról. de José Luis Abellán. México, UnAM, 1990, pp. 31-110.

${ }^{3}$ Cf. Joaquín Xirau, Obras completas. II. Escritos sobre educación y sobre el huma- 
Que todas estas referencias sean más o menos puntuales en el conjunto de las obras de estos autores no implica que sean insignificantes. En los tres casos, la reflexión sobre la Independencia constituye un fragmento de toda una constelación semántica, cuyo eje es la singularidad del pensamiento iberoamericano en el contexto de la racionalidad filosófica occidental. El acervo humanista de dicho pensamiento, tan ligado a la experiencia de América; su presunta condición "asistemática" y su vinculación histórica con la educación; sus concomitancias con otras formas expresivas tales como la poesía, la narrativa, la mística e incluso la oratoria; sus carencias y limitaciones, sus lagunas historiográficas y, al mismo tiempo, su potencial hermenéutico-crítico y sus amplias expectativas futuras, son algunas de las cuestiones que identifican dicha constelación, la cual no se conformó de manera gratuita. Más allá del obvio interés de todo pensador por conocer la tradición desde la que piensa, esta reflexión exiliada sobre las condiciones de posibilidad de lo que podríamos denominar un "pensar en español" respondió a una doble e indisociable circunstancia crítica.

En primer lugar, la circunstancia del propio exilio, tanto por sus causas como por su ubicación. El momento de crisis e indigencia profundas por el que atraviesa la cultura española tras la Guerra civil invita -si es que no obliga- a una cierta "salvación" de la propia tradición, a punto de diluirse bajo las ignorancias, los olvidos y las tergiversaciones tradicionalistas propias de la España oficial. Esta "salvación" encontrará además unas posibilidades de enriquecimiento sustanciosas y hasta entonces desconocidas en el nuevo horizonte intelectual mexicano. El amplio rescate gaosiano de un pensamiento de lengua española ${ }^{4}$ la reivindicación que Xirau planteará del humanismo hispánico, ${ }^{5}$ y los textos que, aun de manera puntual, Nicol dedicará a la actualidad de clásicos como Vives, Vitoria y, sobre todo, Suárez, ${ }^{6}$ o al "problema de la filosofía hispánica, ${ }^{7}$ llevan de alguna manera esta impronta. A la luz del exilio, pensar en español significará algo que trasciende la demarcación española ${ }^{8}$ y que,

nismo hispánico. Ed. de Ramón Xirau. Madrid / Barcelona, Fundación Caja de Madrid / Ánthropos, 1999, pp. 534-551 y 565-571, respectivamente.

${ }^{4} C f$., sobre todo, J. Gaos, Obras completas, vol. v y vi, y Obras completas. VIII. Filosofía mexicana de nuestros días. En torno a la filosofía mexicana. Sobre la filosofía y la cultura en México. Pról. de Leopoldo Zea. México, unam, 1996.

${ }^{5} \mathrm{Cf}$. J. Xirau, Obras completas, vol. II.

${ }^{6} C f$. los artículos "Libertad y comunidad. La filosofía política de Francisco Suárez" (1948); "Propiedad y comunidad. Suárez frente a Locke y Marx" (1948), y "La rebelión del individuo" (1947), en Eduardo Nicol, La vocación humana. Present. de Enrique Hülsz. México, Conaculta, 1997, pp. 246-292.

${ }^{7}$ Así se titula uno de sus libros, publicado por primera vez por Tecnos en 1961.

${ }^{8}$ En este sentido discurrirá la identificación del exilio con un "redescubrimiento" de América. Los españoles -había dicho Gaos- "hicimos un nuevo descubrimiento de 
haciéndolo, tampoco se limitará a continuar sin más las tendencias de la filosofía española en este sentido de las décadas anteriores. La visión organicista de Iberoamérica planteada por Xirau implicará una cierta rectificación de los resabios "panhispanistas" y regeneracionistas que pervivían en el americanismo de Rafael Altamira, aun participando ambos de una misma tradición filosófico-cultural como la krauso-institucionista. ${ }^{9}$ Gaos, por su parte, imprimirá un palpable cambio de acentos a la razón circunstancial de su maestro Ortega y Gasset, cuyo foco iluminador ya no será el "concepto", propio de la cultura germánica, ${ }^{10}$ sino precisamente aquello que este último nunca había llegado a rescatar, aun a pesar de su programa de salvación de la circunstancia española por medio de una filosofía de la cultura ${ }^{11}$ o de sus experiencias argentinas de 1916 y 1924: una tradición de pensamiento en lengua española común a España y América, ${ }^{12}$ rica precisamente por su "precariedad" conceptual o, dicho de una manera afirmativa, por su doble vocación estética y político-pedagógica más que "científica" o sistemática.

También Nicol, aun desde una concepción de la filosofía tan contrapuesta a la de Gaos por la vocación "científica" y "sistemática" que le atribuye -bien es cierto, en un sentido muy distinto del idealista-, advirtió la miopía de Ortega ante la inteligencia americana en particular. La Revista de Occidente, por ejemplo:

América. Sabíamos de la América española, pero qué diferente vivir su vastedad y diversidad en el presente, su profundidad y complejidad por el pasado y a su juventud, su fermentar de formación, y por las tres cosas su plétora de posibilidades de futuro" ("Los transterrados españoles de la filosofía en México", en Obras completas, vol. VIII, p. 238). Por su parte, Nicol se refirió al exilio como "...una especie de nuevo descubrimiento de América, en el cual, por lo que se refiere a la filosofía, lo que predominaba era una cierto rubor por el retraso del hallazgo, y un cierto júbilo en reparar la culpa que pudo haber en la ignorancia anterior" (E. Nicol, op. cit., p. 119).

${ }^{9}$ Sin dejar esta tradición, Xirau sintonizaría mayormente con el americanismo de Rafael María de Labra. Lo he apuntado en "El krausismo ante la pervivencia del colonialismo", en Solar. Revista de Filosofía Iberoamericana, núm. 4, 2008, pp. 81-99.

${ }^{10} \mathrm{Cf}$. sus célebres Meditaciones del Quijote (1914), especialmente la "Meditación preliminar".

${ }^{11} \mathrm{Tal}$ es el hilo conductor de dichas Meditaciones.

12 "Es de sentir que Ortega mismo no viera, es decir, en la raíz, viviera desde el primer momento la unidad de la circunstancia hispano-americana, sino a la América hispánica tan sólo como una circunstancia más dentro de la universal - el motivo de sus relaciones con América: entusiasmo, reconocimiento de influjo, una idea del continente como la insinuada en secuencia de Hegel, un abandono del continente como el que acaba de hacer" (J. Gaos, Obras completas, vol. vI, p. 76). Aun de manera muy escueta y poco fluida, Gaos asocia la visión orteguiana de América con la hegeliana (eurocéntrica y peyorativa, pese a dicho "entusiasmo"), aludiendo además al retorno de su maestro a la España de Franco tras su amarga estancia en Argentina en 1939. 
[...] ¿no hubiera podido formar una colección de filosofía hispánica en la que figurasen, entre otras tantas obras, La existencia como economía, como desinterés y como caridad y El peligro del hombre, de Antonio Caso; la Estética general y la Estética aplicada, de Déustua; la Libertad creadora y El concepto de la ciencia, de Korn; las Proyecciones de la intuición, de Molina; O mundo interior, de Marias Brito; la Lógica viva, de Vaz Ferreira? Sí más no. España hubiera podido ser informada por los viajeros, Ortega sobre todo, que tuvieron oportunidad de conocer algunos de estos contemporáneos suyos cuando estaban en su madurez. ${ }^{13}$

Sin embargo - prosigue Nicol-, Ortega y otros hicieron "un redescubrimiento de Europa" a costa de "la pérdida de América". ${ }^{14}$

Pero, en segundo lugar, esta reflexión exiliada sobre la propia tradición, enriquecida al amparo de la circunstancia mexicana, encauzará toda una respuesta a la crisis radical por la que entonces atraviesa la propia civilización europea, consumida bajo la barbarie totalitaria y la racionalidad instrumental. La conciencia del fracaso radical de la Ilustración bajo esa barbarie también es acicate para rastrear posibles alternativas a la misma en una difusa y escasamente reconocida modernidad iberoamericana, cuya actualidad bien podría inspirar nuevas y liberadoras interpretaciones del $\log o s-\mathrm{O}$, en el caso de Nicol, un renacimiento del mismo frente a sus derivas tecno-científicas contemporáneas. En este sentido, la reflexión -a menudo reivindicativa- sobre un "pensar en español" guardará sugerentes conexiones con una honda conciencia de crisis de la racionalidad filosófica como tal. Tanto el escepticismo disolutivo que impregna la "filosofía de la filosofía" de Gaos ${ }^{15}$ como el deterioro radical de la experiencia del mundo que motivan la fenomenología de la conciencia amorosa de Xirau, ${ }^{16}$ como el nuevo irracionalismo tecno-científico que lleva a Nicol a plantear una "revolución en la filosofía", ${ }^{17}$ guardan una mayor o me-

${ }^{13}$ Cf. E. Nicol, El problema de la filosofía hispánica. México, FCE, 1998, p. 116.

${ }^{14}$ Ibid., p. 123.

${ }^{15}$ Así se titula, como bien es sabido, uno de sus principales libros. Cf. J. Gaos, Obras completas. VII. Filosofía de la filosofía e historia de la filosofía. Pról. de Raúl Cardiel Reyes. México, unAM, 1987. Confróntese también sus artículos "¿Son filosóficos nuestros días?" y "La situación de la filosofía en el momento presente", en J. Gaos, Obras completas. III. Ideas de la filosofía (1938-1950). Pról. de Abelardo Villegas. México, UNAM, 2003, pp. 243-268.

${ }^{16}$ Cf. J. Xirau, "Amor y mundo [1940]", en Obras completas. I. Escritos fundamentales. Ed. de Ramón Xirau. Madrid / Barcelona, Fundación Caja de Madrid / Ánthropos, 1998, pp. 133-262.

${ }^{17}$ Cf. E. Nicol, su "trilogía": El porvenir de la filosofía. México, FCE, 1972; La reforma de la filosofía. México, FCE, 1980, y La revolución en la filosofía. Crítica de la razón simbólica. México, FCE, 1982. 
nor complicidad con dicha reflexión, aun cuando en algunos momentos -en el caso, concretamente, de Nicol- ésta sea indisociable de un contrapunto crítico severo. ${ }^{18}$ "Pensar en español" no será por tanto una cuestión local o regional, sino que articulará respuestas a dicha crisis. Adquirirá una distinción universal y una singular responsabilidad de reconducir la racionalidad occidental. Y es en medio de este rescate afirmativo de la propia tradición, que la Independencia supondrá todo un punto de inflexión a la hora de trazar su evolución y su constelación de nexos y cesuras, de rupturas y continuidades, no sólo históricas, sino también semánticas. Veámoslo con un poco más de detenimiento.

\section{José Gaos: Independencia y autorreflexión}

De los tres filósofos referidos, Gaos fue el que concedió a la reflexión sobre la Independencia una mayor relevancia. Dos notas fundamentales podrían distinguirla. En primer lugar, la ejemplariedad de aquellos pensadores involucrados de alguna manera en la Independencia -ya fuera como precursores, partícipes activos o herederos de la misma- respecto de la caracterización gaosiana de un pensamiento de lengua española. En segundo lugar, la relevancia de la Independencia a la hora de infundir legibilidad hermenéutica e historiográfica en la historia de dicho pensamiento.

Dicha ejemplariedad no es exclusiva de los pensadores de la Independencia, pero éstos significan poderosamente aquellos perfiles que Gaos había atribuido al pensamiento hispano-americano en la primera parte de Pensamiento de lengua española, en polémica con concepciones de la filosofía preestablecidas en función de su carácter metafísico y sistemático, y actualmente en crisis. Se refiere Gaos a un perfil, en primer lugar, estético -más que metódico y sistemático-, pues sus autores gustan de la calidad literaria, optando por el ensayo como género expresivo fundamental -sin olvidar la literatura de ficción, la lírica y la poesía, la correspondencia epistolar y hasta la oratoria-; muestran predilección por temas estéticos, plasmada ya sea en la crítica literaria o de arte, en la elaboración teórica de dichos temas o en concepciones del mundo de inspiración estética; y porque, en definitiva, afrontan cualquier otra temática con un mayor o menor talante estético. Pero, en segundo lugar, el pensamiento de lengua española muestra también un perfil eminentemente político en el

${ }^{18}$ A propósito de la tendencia personalista de la filosofía española contemporánea, especialmente aquella desarrollada bajo el influjo de Ortega. Lo he expuesto en "Eduardo Nicol ante el proyecto de un pensamiento en lengua española", en Relaciones. Estudios de Historia y Sociedad, vol. 28, núm. 112, 2007, pp. 105-134. 
amplio sentido del término, esto es, entendido como organización de una comunidad cultural y como reformismo de la nación, bajo el acicate, a menudo, de la nostalgia del desterrado, y en un doble y complementario horizonte: las independencias y subsiguientes procesos constituyentes de las naciones americanas, y la meditación, en el caso español, sobre la decadencia. De ahí un tercer perfil fundamental, de signo pedagógico, que acentúa la dimensión específicamente formadora o educadora de todo pensamiento, palpable en episodios tan relevantes como el krausismo español o el positivismo latinoamericano, en la abundancia de "filósofos-maestros" y "educadores de pueblos", o en el cultivo del ensayo en tanto que prosa didáctica. Entre todos estos temas y formas "se hace patente una unidad, que viene a ser la característica radical del pensamiento hispano-americano, aquella sobre la que gravita su significación misma. Puede formularse así: una pedagogía política por la ética y más aún la estética; una empresa educativa, o más profunda y anchamente, formativa o reformadora, de independencia, constituyente o constitucional, de reconstrucción, generación, renovación..." En definitiva, un pensamiento entendido como "potencia histórico-cultural" o "potencia histórico-vital humana". ${ }^{19} \mathrm{O}$, dicho de otra manera, un pensamiento "inmanentista" o elevador de la propia circunstancia "a conciencia de sí", cuyo objeto primordial es "este mundo, esta vida, el más acá”, y en cuya palabra "está entrañada la acción misma”; algo que -sugiere Gaos- el programa orteguiano de "salvación de las circunstancias" expuesto en las célebres Meditaciones del Quijote culminaría al expresarlo de una manera compleja, pero que en realidad podría rastrearse en la obra de autores como Rodó, Sarmiento o los jesuitas criollos del siglo XVIII.

No es difícil adivinar la significación de la Independencia en esta caracterización. Desde la obra precursora de esos mismos jesuitas criollos -si es que no desde la obra anterior, un siglo antes, de Carlos de Sigüenza y Góngora- hasta aquellos pensadores que recogieron críticamente los resultados del proceso emancipador -la generación argentina de 1834 o el primer liberalismo mexicano- pasando por aquellos que fueron contemporáneos del mismo empezando por el propio Bolívar, el perfil del filósofo entendido como un educador de pueblos, un político con ideas e incluso un hombre de Estado, un teórico de la identidad nacional o un reformador de la nación, es de alguna manera constante. El mencionado Sigüenza sería:

El punto de partida de un pensamiento cuyo primordial objeto empieza por ser la América autóctona, aborigen y la Colonia en su peculiaridad cultural, nacional, para acabar siendo la Independencia política de la misma, y la constitución reiterada reconstitución de los países indepen-

${ }^{19}$ J. Gaos, Obras completas, vol. VI, pp. 87 y ss. 
dientes, y, cuando menos, una filosofía original de estos países. El objeto, pues, más inmediato en el espacio y en el tiempo. Hispanoamericano hasta este punto. No universal, sino en la medida y en la forma en que el hispanoamericano requiera un objeto tal. Lo que es válido incluso para la filosofía importada desde los jesuitas hasta la última generación. Todos la importan en una afanosa intención, simplemente más o menos consciente o expresa, de contribuir a la renovación intelectual, cultural, nacional, de la patria, a la creación de una filosofía original de la patria o siquiera hispanoamericana. Tampoco un objeto trascendente sino en la misma medida [...] Un pensamiento, por tanto, primordialmente político, en el amplio sentido relativo a la comunidad cultural en su integridad que comprende hasta el sentido más estricto. Amplio sentido en el cual lo político es pedagógico en un sentido igualmente amplio, el de educativo, formador, creador, de la comunidad cultural, que comprende también hasta el sentido más estricto del término. ${ }^{20}$

La experiencia de la Independencia aparece así como uno de los resortes -si es que no el principal- del pensamiento hispano-americano, ${ }^{21}$ de su inmanentismo y de la significación de este último en tanto que apropiación radicalizada, y en este sentido original, de la Ilustración. O como dirá en En torno a la filosofía mexicana (1952), una importación "electiva" y "aportativa", y no meramente imitativa. Tal será para Gaos el sentido que la Independencia imprimirá a la filosofía mexicana desde el siglo XVIII en adelante, trazando una línea divisoria a lo largo de su historia; pues si durante la Colonia toda importación se realiza "desde fuera" o con "espíritu de metropolitano", a partir de dicho siglo se hará "desde dentro" o con "espíritu de espontaneidad, independencia y personalidad nacional y patriótica creciente", entendiendo los términos "desde fuera" y "desde dentro" no en sentido geográfico o espacial, sino "desde fuera y desde dentro del espíritu mexicano". ${ }^{22}$ Es decir, desde una razón circunstancial que metaboliza originalmente el pensamiento declarado universal hasta el punto de revertir luego sobre él enriqueciéndolo sustancialmente, si es que no cuestionándolo. O con palabras de Gaos, desde

${ }^{20}$ Ibid., vol. v, p. 34.

21 "De la Independencia y proceso de constitución de las naciones hispano-americanos, incluso la española, es justamente coetáneo el pensamiento hispano-americano contemporáneo. No simplemente coetáneo. La simultaneidad es en este caso, como en los más, manifestación de las relaciones más sustanciales. El pensamiento hispanoamericano contemporáneo viene siendo órgano principal de la Independencia y proceso de constitución de las naciones correspondientes [...]" (J. Gaos, Obras completas, vol. VI, p. 77).

${ }^{22}$ J. Gaos, Obras completas, vol. vIII, pp. 306 y ss. 
una "inserción de lo importado en lo nacional" a una "inserción de lo nacional en lo importado". ${ }^{23}$ En este sentido, la Independencia será la experiencia desencadenante de un pensamiento "fundamentalmente político, nuclear y formalmente estético" que no sólo es "promoción voluminosa y valiosa de la Ilustración [...] y últimamente del 'inmanentismo' del hombre moderno", sino también "la más reciente aportación y no menor aportación de Hispanoamérica a una filosofía propia y a la universal". ${ }^{24}$

Pero la relevancia de la Independencia en la fenomenología gaosiana del pensamiento de lengua española se advierte también, en segundo lugar, en un rasgo que estas últimas citas traslucen. Concretamente, en su periodización más elemental. Para Gaos, dicho pensamiento se dividiría en dos grandes edades, marcadas precisamente por la Colonia y la Independencia. La primera se caracterizaría por la importación de un pensamiento ajeno que, aun a pesar de sus fermentos jurídicos y antropológicos, significados en el debate sobre la "legitimidad de la conquista" y la "humanidad del indio", no llegará a conformar una subjetividad propia o independiente de los intereses de la metrópoli. Sería por tanto "pensamiento en la América española", pero no "de" ella. Un pensamiento americano por su objeto, pero no por su sujeto. Esto último sería precisamente lo característico del pensamiento de la Independencia, que, en un sentido muy amplio, comprendería toda la segunda edad hasta el presente, caracterizándose por ese triple perfil arriba apuntado, tan ligado a la conformación de identidades nacionales y culturales. La impronta de la Independencia persistirá así tras la fundación de las nuevas naciones; por ejemplo, en el "positivismo sui generis" de Lastarria, Barreda, Hostos o Martí, en la medida en que hacen de él "una aplicación del pensamiento a los problemas de la realidad inmediata en el espacio y en el tiempo" - de manera paradigmática Barreda, quien usa el positivismo "como instrumento de consolidación de la Reforma",$-{ }^{25}$ o en el pensamiento superador del mismo, "espiritualista" en algún sentido y en algún momento, desde Rodó, Deústua o Sierra -el Sierra "tardío", habríamos de puntualizar- hasta Caso, Vasconcelos o Ramos, quienes adaptan las diversas tendencias de la fenomenología, el existencialismo y la filosofía de los valores a los problemas de la propia circunstancia. ${ }^{26}$ En definitiva, de la nueva identidad a que la Independencia dio lugar.

Esta periodización sería además extensible al conjunto de Hispanoamérica. Para Gaos, la meditación sobre la decadencia que recorre todo el pensamiento español del último siglo y medio desde Larra hasta Ortega y su escuela, pasando

${ }^{23}$ Ibid., p. 308.

${ }^{24} \mathrm{~J}$. Gaos, Obras completas, vol. vi., p. 55.

${ }^{25}$ Ibid., p. 30.

${ }^{26}$ Cf. ibid., p. 32 . 
por el krausismo, la generación del 98 e incluso el tradicionalismo, es del todo análoga a la reflexión sobre la Independencia, como lo son las meditaciones sobre la Colonia - en el caso de América- y sobre la grandeza -en el caso de España. En realidad -apuntará Gaos en este sentido- la reflexión sobre las causas de la cerrazón de España a la modernidad, especialmente a su promoción científica, y sobre sus posibles remedios, constituye un motivo muy similar al de la independencia cultural y política, como lo son entre sí el europeísmo de la inteligencia emancipadora y la "europeización" surgida de la conciencia decadente, la preferencia de unos y otros por la prosa estética y didáctica, y, en definitiva, la aplicación del pensamiento a los problemas derivados "de la realidad más inmediata en el espacio y en el tiempo". "Pensamiento hispanoamericano y pensamiento español parecen, pues, integrar una unidad, aun en la edad de la independencia del uno, de la decadencia del otro: la unidad de un pensamiento que se puede llamar pensamiento de los países de lengua española, por ser ésta la que ha venido a prevalecer en todos", y que se articula "en las dos edades, de la grandeza y la Colonia, de la Independencia y la decadencia, de las que ésta es aún la nuestra, es la contemporánea". Es decir, sobre la distancia geográfica o espacial entre España y América, tan asociada al antagonismo político derivado de la dominación colonial, prevalecería una comunidad semántica y una sintonía histórica cuyo quicio radicaría en una lectura de la Independencia que también incluye a la metrópoli en tanto que entidad llamada a emanciparse de su propio lastre imperialista. Para Gaos, salir de la decadencia tiene esta significación. Por eso independencia no es "un separarse y distanciarse de las colonias exclusivamente de la metrópoli y del Imperio como en el espacio". Es más bien "un hacerse independientes en el tiempo colonias y metrópoli de la unidad imperial, dejando de ser metrópoli y colonias para pasar a ser naciones igualmente independientes, no sólo, pues, en lo cultural, sino también en lo político". Lo cual no obsta para que la más arraigada presencia del Imperio en la metrópoli favorezca

[...] que la independencia cultural se inicie en las colonias antes que en la metrópoli, que la política se logre en las continentales desde la primera mitad del siglo pasado, en las insulares desde la segunda, en la ex metrópoli peninsular se haya malogrado hasta hoy [...] Pero la marcha de la historia es hacia una nueva unidad de España y la América española: la de una pluralidad de repúblicas hispanoamericanas, España la última en el tiempo. La unidad de que sería causa y efecto la integrada por el pensamiento de la independencia y la decadencia. ${ }^{27}$

${ }^{27}$ Ibid., pp. 42 y ss. 
En virtud de esta representación "histórica, temporal", el Imperio viviría "en los metropolitanos de la metrópoli y de las colonias satisfechos de él, pero también en los coloniales de las colonias o de la metrópoli fieles a él”, mientras que la Independencia haría lo propio "en los coloniales de colonias o metrópoli que aspiraban a ella, pero también en los metropolitanos de colonias y metrópoli que simpatizaron con ellos". Asimismo, la Independencia "sigue viviendo en los ciudadanos de la antigua metrópoli que aspiran a que se logre la independencia política de ella y que simpatizan con la de las antiguas colonias, y en los ciudadanos de estos países amantes de la independencia no sólo del suyo, sino también de los demás y de la antigua metrópoli"; mientras que el Imperio "pervive en los ciudadanos de la última y de estos países que lo añoran en una forma u otra, en una u otra medida". En definitiva, "imperios y repúblicas no están arraigados a los suelos: radican en las almas que los pisan con los pies de sus cuerpos". ${ }^{28}$

Gaos desliza así el antagonismo metrópoli-colonias hacia otro más amplio, entre Imperio e Independencia, entendidos como los núcleos semánticos de una mentalidad o una conciencia ideológica y no solamente como un status político, aun cuando ambos factores se encuentren estrechamente ligados. En virtud de ese arraigo en las almas más que en los suelos, la Independencia adquiere una significación casi superlativa. Lejos de agotarse en un acontecimiento estrictamente político o apegado a la gestación de nuevas nacionalidades, perfectamente acotado en el espacio y en tiempo, y generador de un pensamiento más o menos exclusivo del mismo, divide la totalidad del pensamiento de lengua española y condiciona poderosamente su evolución hasta el presente. De hecho, el propio exilio español republicano del 39 guardaría una conexión con ella: para Gaos, España es la única nación de Hispanoamérica que aún no ha culminado su proceso emancipador. Mientras que las restantes naciones lo habrían hecho espiritualmente a partir del siglo XVIII mediante "una constitutiva ideología ochonovecentista, democrática, liberal, antiimperialista"; políticamente en el primer tercio del XIX - en el caso de las repúblicas continentales- o a finales del mismo - en el caso de las insulares-, España permanece aún "colonia de sí misma" y es "la única nación hispanoamericana que del común pasado imperial queda por hacerse independiente, no sólo espiritual, sino también políticamente". ${ }^{29}$ La Independencia tendrá así esta actualidad añadida. Constituirá un poderoso motivo para desahogar una cierta crítica del presente, si bien a costa de sostener una visión un tanto idealizada de las repúblicas hispanoamericanas. Tal y como apuntará Sánchez Vázquez a propósito del concepto gaosiano de "transtierro", Gaos obvió el ca-

${ }^{28}$ Ibid., p. 43.

${ }^{29}$ J. Gaos. Obras completas, vol. vI, p. 40. 
rácter frustrante de las independencias americanas, las cuales no lograron impedir toda suerte posterior de caudillismos, políticas autoritarias y soberanías endebles, tan dependientes de intereses económicos y geopolíticos neocolonialistas. ${ }^{30}$

\section{Joaquín Xirau: Independencia y tradición}

Las alusiones de Xirau a las independencias iberoamericanas son muy puntuales aunque no meramente anecdóticas. Su ensayo "Humanismo español (ensayo de interpretación histórica)" (1942), que presuntamente sería el esbozo de un futuro libro sobre esta misma cuestión que Xirau no llegó a escribir, ${ }^{31}$ toma "como punto de partida el estado de ánimo de los grandes libertadores hispanoamericanos del siglo XX". A propósito de algunos fragmentos de la correspondencia de Bolívar, apunta Xirau la tesis de la guerra de Independencia como una guerra civil, acontecida no sólo en América sino también en España, en la que se dirimirían dos concepciones de la hispanidad, una liberal y otra imperialista, la cual trascendería el conflicto, más superficial, entre "españoles americanos" y "españoles europeos". Es decir, análogamente a la concepción gaosiana, se trataría de un conflicto ideológico más que geopolítico, común a ambas orillas, y que encontraría en la invasión napoleónica de la península Ibérica su detonante inicial más que su razón de ser. Por eso para Xirau, "Bolívar es el tipo del patriota español", 32 como lo fuera en su día Las Casas, como lo eran también Mina o Riego - españoles que abogaron por la emancipación americana-, o como lo serán después Larra o los escritores de la generación del 98, pues todos ellos reivindicarían, tras sus denuncias del atraso, el despotismo o la decadencia españolas, una concepción liberal de lo español, común a sus vertientes americana y europea. "Tenemos, por tanto, que no sólo la guerra de la Independencia americana es una guerra civil sino que esta guerra tiene lugar aquí y allá. En una y otra parte hay una buena y una mala causa y ambas son defendidas por españoles". La "buena causa" reside para Xirau en "la comunidad de intereses de los libertadores de ambos continentes". ${ }^{33}$

Hasta aquí Xirau no hace sino reproducir lo más elemental de la lectura de la Independencia que podríamos denominar "liberal", ligada al tópico de

${ }^{30}$ Cf. "Del destierro al transtierro", en Claves de Razón Práctica, núm. 101, abril, 2000, pp. 4-9; también en Alicia Alted y Manuel Llusia, dirs., La cultura del exilio republicano español de 1939. Madrid, UNED, 2003, vol. II, pp. 627-636. 2 vols.

${ }^{31}$ Así lo reconoce él mismo hacia el comienzo de dicho ensayo ( $c f$. J. Xirau, Obras completas, vol. II, p. 535, n. 1).

32 Ibid., p. 535.

33 Ibid., p. 536. 
"las dos Españas" y del que Gaos también participa, aun con un discurso más complejo. Sin embargo, su lectura resulta más singular cuando plantea claves genealógicas de esa concepción liberal común a ambos mundos: que sea liberal no significa que se identifique sin más con los valores de la Enciclopedia, de la Ilustración o de la Revolución francesa, al menos tal y como se han desarrollado canónicamente en Europa. Para Xirau, la influencia de estos valores es tan innegable como universal en su época, pero superficial en el caso de los movimientos independentistas de 1810 , los cuales se habrían nutrido ideológicamente de la propia tradición: "si bien las ideas francesas son el incitante, la causa ocasional e inmediata de los ideales que los informan [...] su causa verdadera, aquella que los define y les presta su perfil y su fisonomía peculiar, se halla en estratos mucho más profundos de la historia". En realidad, estas "nuevas ideas actúan sobre un espíritu antiguo y largamente elaborado", sobre un espíritu liberal que recorrería toda la tradición del humanismo hispánico, se remontaría nada menos que hasta la personalidad medieval de Ramón Llull y cuya clave hermenéutica no sería otra que el organicismo. "Si hay en la tierra una constelación humana con fisonomía cierta" -afirma en este sentido- "ésta es sin duda la que constituye el cuerpo de la comunidad hispana", equivalente a "la unidad orgánica, expresiva, original, múltiple y contradictoria de una persona". 34

Xirau había sido discípulo de Jaime Serra Hunter en el horizonte de la llamada "Escuela de Barcelona" y también de Ortega -si bien nunca fue orteguiano-, así como un buen conocedor de las corrientes fenomenológicas -tanto alemanas como francesas- de su época. Pero su maestro, "por encima de todos y en el sentido más pleno de la palabra”, tal y como él mismo recordará en el exilio, ${ }^{35}$ no había sido otro que Manuel B. Cossío, sucesor de Francisco Giner de los Ríos al frente de la Institución Libre de Enseñanza de Madrid y a través de quien recibiría una honda impronta de una tradición filosófico-pedagógica tan ligada al organicismo como la del krausismo. No en vano dedicará Xirau a la personalidad y la obra de Cossío, así como a su contexto cultural, político y pedagógico, un extenso libro en el que recorrerá los principales registros de este organicismo, especialmente aquellos relacionados con la educación. ${ }^{36} \mathrm{La}$ "dialéctica integradora" ${ }^{37}$ característica del pensamiento de Cossío se hará así notar en Xirau. Lo hará en sus escritos teóricos o fenomenológicos, en los que lo dado en la conciencia significará trascendencia en la inmanencia, identidad en la alteridad, extroversión de una intimidad fecundada por la experiencia

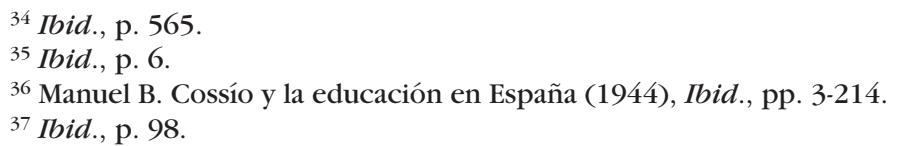


primaria del amor, o perspectiva entendida como presencia polimórfica latente de una realidad inagotable e interconectada ${ }^{38} \mathrm{Y}$ lo hará, de manera más diáfana, en la reconstrucción que Xirau esboza del humanismo hispánico, desde sus mismos balbuceos medievales hasta el presente.

En su libro Vida y obra de Ramón Lull. Filosofía y mística (1946), Xirau rastreará los orígenes de este humanismo, en medio del crisol hispánico que configuran la herencia greco-latina, el legado judeocristiano y la presencia árabe. Los "hábitos de liberalidad y democracia" generados al amparo de esta triple herencia mediterránea, plasmados en "la más amplia libertad espiritual y religiosa y la igualdad jurídica y social entre los miembros de las diversas creencias", ${ }^{39}$ en contraste con la cerrazón y el encastillamiento de Europa, supondrán para Xirau la piedra angular de toda una tradición organicista que encontrará momentos álgidos en la sociedad natural universal de Vives, en el derecho internacional de Vitoria o en la empresa misionera en América. Incluso durante los dos siglos de "evasión anómala" y de repliegue autoritario que transcurren desde la muerte alegórica del Quijote hasta la muerte real de Fernando VII, dicha tradición -la auténtica para Xirau, que no debe confundirse con el tópico de la "España negra" o la "España católica" - ${ }^{40}$ permanecerá latente en "la voz reconvertora, admonitoria o sarcástica" de autores como Quevedo, Feijoo, Jovellanos, Larra o el propio Bolívar... La Independencia, entendida como un proceso común a España y América, sería precisamente el gran desahogo de esa tradición reprimida y la gran respuesta a la "desintegración" de la comunidad hispánica a que habría conducido dicho repliegue. Bajo la lente organicista de Xirau, decadencia es sinónimo de desintegración. Lo anómalo es tal por romper el "estado natural" de "unión" propio del "mundo de la tradición española". Por eso la "desintegración actual" de Iberoamérica obedece a "azares históricos independientes de su íntima naturaleza. De ahí que sus miembros desarticulados se muevan con gesto patológico, dolorido y desazonado". Para Xirau, el gran síntoma "de esta patología es el estado de guerra civil en que constantemente inciden y del cual las guerras de Independencia son la primera y general manifestación" ${ }^{41}$ Independencia significaría entonces catarsis regeneradora y restitución actualizada de una tradición auténtica de signo organicista, común a España y América, que poco o nada tendría que ver con el pasado imperial evocado e invocado por el tradiciona-

${ }^{38}$ Cf. sus libros Amor y mundo (1940) y Lo fugaz y lo eterno (1942), recogidos en Obras completas, vol. I. "Sólo mediante una perspectiva integral que trate de recoger todos los aspectos y todos los puntos de vista hallaremos una salvación para el mundo y para la ciencia que trata de iluminarlo", dirá por ejemplo en el primero de ellos (p. 191).

${ }^{39}$ J. Xirau, Obras completas, vol. II, p. 233.

${ }^{40}$ Ibid., pp. 12 y ss.

${ }^{41}$ Ibid., pp. 565 y ss. 
lismo. Proyectos de integración iberoamericana como los del conde Aranda o Bolívar tendrían esta connotación.

Xirau saldría así al paso de la tópica objeción, según la cual, la ausencia de un proceso ilustrado previo en Iberoamérica, imposibilitado bajo los bagajes autoritarios de la propia tradición -auténtica o no-, habría frustrado el proceso emancipador. Planteamientos como los de Alberdi y Sarmiento en el contexto de la generación argentina de 1834, seguimientos críticos de un liberal maldito como Blanco White o la propia conciencia de fracaso de Bolívar dan buena cuenta de ello. ${ }^{42}$ Para Xirau, por contra, esa tradición propia, lejos de agotarse en esos bagajes, sería portadora de una singular modernidad, velada y desplazada, cuyo núcleo sería un organicismo integrador de connotaciones amplias, políticas y epistemológicas, religiosas y culturales. Su profundidad genealógica y su enraizamiento nada menos que en la tolerancia española medieval, le ofrecería un sólido sustento. ${ }^{43}$ Marcando algunas diferencias respecto de la lectura gaosiana, la gran clave hermenéutica de la Independencia no sería ya una apropiación original de la Ilustración, sino algo más ambicioso como la latencia de toda una tradición propia, en virtud de la que sus aparentes fracasos serían en realidad signos de otra manera de entender la libertad. Que la Independencia no se ajuste a los patrones revolucionarios de la Ilustración no significa, para Xirau, empobrecimiento, sino autenticidad.

No cabe duda de que Xirau tiende a una visión un tanto idealizadora de la tradición hispánica y, en consecuencia, de la Independencia, si bien desde un talante diferente del gaosiano. No ya desde una visión ilustrada, sino también desde la crítica intercultural y poscolonial o desde la visión anamnética del pasado significada en conceptos como los de "memoria histórica" y "responsabilidad histórica”, en los que ahora no nos detendremos, resulta problemático sostener una visión amable y reconciliadora como la de Xirau. Para el pensamiento crítico, todo organicismo es sospechoso de omisiones y olvidos, de reconciliaciones en falso y de reduccionismos implícitos. En este caso, de la omisión de la violencia conquistadora y colonizadora, y del duelo y la deuda generados por ella; de las asimetrías entre una orilla y la otra y de las contradicciones entre unos sujetos culturales y otros; de la identificación de un supuesto principio metafísico de organización universal con un principio cosmovisional concreto -aun a pesar de su hegemonía en Occidente- como el cristiano.

${ }^{42} C f$. por ejemplo Eduardo Subirats, Memoria y exilio. Barcelona, Losada, 2003, pp. 195-225.

${ }^{43}$ Este planteamiento genealógico de Xirau invita a rescatar una obra historiográfica del exilio español tan relevante como infravalorada, incluso al día de hoy, como la de Américo Castro. Cf. A. Castro, España en su historia: cristianos, moros y judíos. Buenos Aires, Losada, 1948. Reeditado en 1983 (Barcelona, Grijalbo) y en 2004 (Madrid, Trotta). 
En medio de todo, Xirau señaló - aun sin adentrarse en él- un debate de actualidad y no poca complejidad como el que suscita el laberíntico liberalismo hispánico, ${ }^{44}$ y concibió la Independencia como un proceso inacabado. Expresión de una anomalía e incluso una patología más que solución a la misma, desahogo de una mentalidad y una tradición reprimidas más que restablecimiento de las mismas, se trataría de un proceso abierto e inconcluso. Análogamente a la lectura gaosiana, aunque de manera mucho más parca e implícita, la semántica de la Independencia adquiere en Xirau vastas dimensiones. Si su antecedente remoto hay que buscarlo nada menos que en la España medieval, su proyección última apunta hacia un futuro que, utópico o no, pasaría por la realización de tres condiciones indispensables. En primer lugar - escribirá Xirau en 1945, en su artículo "Integración política de Iberoamérica":

La renuncia explícita, leal y decidida a toda idea de imperio, superioridad o dominio y la convicción sinceramente sentida de que todos los valores -incluidos naturalmente los indígenas de América- nos pertenecen por igual a todos en la plenitud de su dignidad histórica. Y en lo que respecta a la España estricta, la afirmación resuelta de que lejos de aspirar a dominio alguno a su único anhelo es darse incondicionalmente a todos porque a todos por igual nos pertenece [...]

[En segundo lugar] La instauración de gobiernos liberales y democráticos en todos los países de la Unión [...]

[Finalmente,] La resuelta adopción de la doctrina federal según la cual la extensión del poder se halla en razón inversa de su intensidad y de que sólo pertenece a los poderes superiores aquellos que es del común interés de todos los círculos subordinados. ${ }^{45}$

Tres condiciones que, si bien son aún irrealizables, instan a "poner las primeras piedras para nuestra tarea de reincorporación intercontinental". En este sentido, dos medidas de orden político - y de no poca actualidad al día de hoy-serían ya realizables a juicio de Xirau: "El reconocimiento de la ciudadanía, en cada uno de los países comprendidos en la Comunidad, a todos los ciudadanos naturales de la península Ibérica y de la América española y portuguesa [...]"; y "El cuidado exquisito de todo lo relativo a las respectivas colonias de emigrantes con objeto de integrarlas con amor a los países de su residencia en íntima coordinación con los intereses de su patria de origen [...]"46

${ }^{44}$ Sobre esta cuestión, $c f$. Francisco Colom, "A la búsqueda del liberalismo hispánico", en Solar. Revista de Filosofía Iberoamericana, núm. 4, 2008, pp. 53-79.

${ }^{45} \mathrm{~J}$. Xirau, Obras completas, vol. II, pp. 568 y ss.

${ }^{46}$ Ibid., p. 570. 
Xirau esbozaba así un proyecto de integración iberoamericana que en última instancia no aspiraba sino a actualizar "el de Bolívar" y "el del conde de Aranda", y en sintonía "con las ideas de Francisco de Vitoria". ${ }^{47}$ Sobre el trasfondo, todo ello, de una teoría organicista y federalista de la nación que asimismo había esbozado en 1943 a propósito del fracaso de la Sociedad de Naciones ante el desencadenamiento de la Segunda Guerra Mundial, ${ }^{48}$ y en virtud de la cual dicho proyecto resultaría ejemplar en el panorama actual de Occidente. Aun de manera implícita, la Independencia se conectaba así, no ya con el exilio español del 39, sino también con la situación de Europa en plena devastación totalitaria.

\section{Eduardo Nicol: Independencia, interdependencia}

La lectura nicoliana de la Independencia guarda algunas analogías con la de Xirau. Conforme a ella, dicho acontecimiento habría traído consigo "un nuevo estilo de comunidad" ${ }^{49}$ en Hispanoamérica que también recogería y proyectaría los vínculos ya contraídos y madurados a lo largo de la convivencia colonial. Aun a pesar de las rupturas políticas con esta última, del surgimiento de nuevos estados como resultado de "un deseo de reforma política" inspirado en "el principio del consentimiento de los gobernados como fundamento de derecho de los gobernantes", ${ }^{50} \mathrm{o}$ de la creación de barreras y fronteras nacionales pervivirían unos vínculos tradicionales con base en los cuales se construirá un nuevo ethos. La comunidad política de la Colonia -afirma Nicol en este sentido- quedó destruida, pero "Subsistía y subsiste la comunidad humana [...], el sentido de una solidaridad entre los hombres de Hispanoamérica, sean del país que sean, y aun cuando sus países respectivos se encuentren en discordia o en estado de guerra", ${ }^{11}$ Las guerras de Independencia, concretamente, lejos de resolverse en "una desvinculación de España", lo harían en "una vinculación más solidaria", pues la "materia" de las nuevas naciones, la "ejemplariedad humana" de la que disponían, "era en gran parte una herencia española". ${ }^{52}$ De ahí el carácter exclusivamente político del proceso emancipador o la necesidad de distinguir, como hicieran Bello, Rodó u Hostos, entre su "necesidad política" y la nece-

${ }^{47}$ Ibid., p. 568.

${ }^{48}$ Cf. J. Xirau, "Sobre la organización de la paz", en Obras completas III. Escritos sobre historia de la filosofía. Artículos y ensayos. Ed. de Ramón Xirau. Madrid / Barcelona, Fundación Caja de Madrid / Ánthropos, 2000, vol. 2, pp. 313-327.

${ }^{49}$ E. Nicol, El problema de la filosofía hispánica, p. 53.

${ }^{50}$ Ibid., pp. 49 y ss.

${ }^{51}$ Ibid., p. 51.

${ }^{52}$ Ibid., p. 53. 
sidad, creada precisamente por dicho proceso, "de mantener y reformar los vínculos reales, no administrativos, con España". ${ }^{53}$

Análogamente a Xirau, Nicol concebiría la Independencia como una suerte de crisis regeneradora de la identidad hispánica, por medio de la cual los viejos vínculos coloniales encontrarían nuevas y más maduras posibilidades de cohesión y, al mismo tiempo, de diferenciación interna. Nicol nunca llegó a sintonizar - de manera explícita, al menos- con el organicismo y menos aún con el krausismo, pero no olvidemos que conceptos como los de comunidad, alteridad o intersubjetividad recorren todo su pensamiento. Es en este sentido que la Independencia se traduciría en esa "vinculación más solidaria" entre las nuevas naciones y la nación española. De ahí su rechazo de la retórica noventayochista cuando llora la pérdida de las últimas colonias, pues con ello "se atribuía retrospectivamente a esas tierras de América un carácter de posesión o dominio y, por tanto, el carácter de algo extraño al propio ser [...,${ }^{54}$ en lugar de algo inherente al mismo.

Nicol también ligó esta lectura de la Independencia a la preexistencia de una tradición en la que encontraría su razón de ser y que, si bien no muestra las ambiciosas dimensiones que en Xirau, encuentra en la experiencia colonial una significación -cultural, más que filosófica- lo suficientemente sólida como para fundamentar una experiencia comunitaria. De nuevo, la objeción de cierto intelecto liberal según la cual el proceso emancipador estaría atravesado por la frustración, el fracaso, la ausencia de una verdadera política revolucionaria y de una ilustración previa, carecería de sentido. En el caso de Nicol, estas ausencias no restarían sentido ni legitimidad a dicho proceso. Aun desde un talante filosófico sensiblemente diferente del de Xirau, coincidiría con éste en concebir la tradición precedente como un argumento y una condición de posibilidad, mucho más que un lastre imposibilitador. De ahí su tendencia asimismo idealizadora, focalizada en este caso en la cultura colonial. Para Nicol, la Colonia no sólo "fue efectivamente la primera empresa de unificación humana, cultural y política que se llevó a cabo en el continente americano", 55 sino que además no estaría animada, en realidad, por un sentido colonialista "en el mal sentido que esta palabra ha adquirido, que es un sentido imperialista" ${ }^{56}$ No sólo estaría exenta de discriminación racial alguna, sino que además el ocaso de la cultura indígena se habría debido, sobre todo, a su asimilación "al mismo nivel superior de vida humana que representaba para todo europeo de aquel tiempo su propia cultura". La cual, significada en la evangelización, ha-

\footnotetext{
53 Ibid., p. 56.

${ }^{54}$ Ibid., p. 54.

${ }^{5}$ Ibid., p. 88.

${ }^{56}$ Ibid., p. 95.
} 
bría impedido una explotación sin mitigaciones y favorecido, por el contrario, un proceso colonizador sin "afán de dominio" ni "sentimiento ofensivo de superioridad", pues "la intención no era pragmática, la meta era puramente espiritual y el método era caritativo, no era político". La finalidad de la Colonia no sería otra, en definitiva, que la humanización, entendida como ingreso en la universalidad occidental, previo reconocimiento del nativo como un igual... y previa enajenación, por tanto, de su cultura autóctona y de su subjetividad originaria. "Así, el amor del hombre como hombre no sólo justificaba, sino que requería incluso la eliminación de su cultura autóctona [...] La idea directriz era la universalidad". ${ }^{57}$ Dicha cultura llevaría entonces en sí misma, dada su supuesta inferioridad, el germen de su propia disolución una vez que entrara en contacto con el logos. Paradójicamente, esas mismas nociones nicolianas de comunidad, alteridad e intersubjetividad, tan jugosas en tantos momentos de su obra y tan fecunda a la hora de rectificar la subjetividad individualista moderna y su afán de dominio objetivado en construcciones excluyentes de la universalidad, quedarían ahora en entredicho por la rigidez con la que el propio Nicol entendió la filosofía, como una reflexión preestablecida e invariable, conforme a los cánones del logos o de la razón occidental, tal y como se gestó en Grecia y evolucionó en Occidente. Quizá sea ésta una de las grandes tensiones que recorren la obra de Nicol: la reivindicación de algo tan precario en la tradición dominante del humanismo occidental como la alteridad por una parte, la fidelidad estricta a una concepción del logos y de la universalidad moldeada por esa misma tradición. El acento en lo segundo inhibe lo primero. De manera explícita en El problema de la filosofía hispánica, en donde Nicol justifica la "eliminación" de la cultura autóctona de América desde una lógica similar a la de Hegel. ${ }^{58}$

Nicol plantearía así una visión de la Colonia que no sin razones Mari Paz Balibrea ha denominado "occidentalista", apoyándose en el término empleado por Walter Mignolo. ${ }^{59}$ Con base en ella, la colonización española de América

${ }^{57}$ Ibid., p. 97.

58 "Sólo cuando el país entero (América: ASC) sea poseído, surgirá un orden de cosas fijo. Los comienzos que en este sentido pueden observarse allí, son de naturaleza europea", afirma Hegel en las Lecciones sobre filosofía de la historia universal. Prólogo de José Ortega y Gasset. Advertencia de José Gaos. Madrid, Alianza, 1989, p. 177, tras plantear una división "absoluta" entre el Viejo y el Nuevo Mundo, a tenor de la supuesta inmadurez, debilidad e inferioridad de la cultura e incluso la naturaleza de este último.

${ }^{59} C f$. su ponencia inédita "Occidentalismo e integración disciplinaria: Eduardo Nicol frente a América". En el caso de "los nuevos países independientes, africanos y asiáticos" -afirma Nicol en este mismo sentido- "autonomía significa, irremediablemente, europeización u occidentalización”. Cf. E. Nicol, El problema de la filosofía hispánica, p. 62. 
merece para Nicol un elogio más que una refutación. Incluso se perfila, en algunos momentos, como una obra casi humanitaria o filantrópica, gracias a la cual Hispanoamérica gozaría de un status cultural análogo al del resto del mundo occidental en el momento de iniciarse su Independencia. "La acción de España en América, su dominio político en ella, si así quiere decirse" -afirma en este sentido- "no representó nunca una opresión del hombre sobre el hombre, fundada en una discriminación racial, sino al contrario. La unidad humana se logró efectivamente desde el siglo XVI. En verdad, ella fue el signo, la justificación moral y jurídica, el ideal mismo de la colonización". ${ }^{60} \mathrm{Nicol}$ obvia así la significación violenta de esta última, así como sus expresiones consumadas de inhumanidad. Soslaya el precio de sus bondades y la horma particular de su concepción universal, llegando a confundir sus grandes resortes ideológicos -civilización, respeto a la integridad personal del indio, evangelización...- con aquello legitimado por estos mismos resortes - reducción del indio, con violencia o sin ella, anegación de culturas autóctonas, opresión militar, imposición de formas de vida... Tiende a confundir la universalidad con una concepción particular de la misma; igualdad con asimilación; la memoria de las injusticias cometidas con la "nostalgia sentimental" 61 o con el supuesto "racismo" de la ideología indigenista, ${ }^{62}$ la diferencia con el desnivel entre culturas supuestamente superiores y culturas declaradas inferiores.

En medio de esta insuficiencia crítica, Nicol desliza no obstante una lúcida desmitificación de la idea ilustrada de tolerancia, basada en un respeto meramente externo al otro que, en el caso del "verdadero" colonialismo -aquel que, contrariamente al español, se caracterizaría por una voluntad imperialista-, se funda "en un sentimiento de superioridad racial, o simplemente en la desnuda superioridad de su poder", carente de "la intención democrática de que todos sean iguales por la cultura y las creencias", cuidándose "por ello muy bien de respetar por fuera las formas de vida nativas y las tradiciones religiosas, a las que se considera como curiosidades exóticas e inofensivas". ${ }^{63}$ Nicol no llega a ser explícito en este punto, pero tras esta objeción asoma la tolerancia liberal y contractualista, individualista y pragmática, con la que él mismo ajustará cuentas en El porvenir de la filosofía desde su visión "comunitaria" de la política, y que tan larga y estrechamente convivió con la devastación colonizadora de otros continentes. Paradójicamente, el elogio nicoliano de la colonización española de América por su arraigo en la modernidad occidental daría pie a una crítica de la expansión canónica de esta misma modernidad; es decir,

${ }^{60}$ E. Nicol, El problema de la filosofía hispánica, p. 100.

${ }^{61}$ Ibid., p. 98.

${ }^{62}$ Nicol plantea una lectura peyorativa de la misma en ibid., pp. 82-96.

${ }^{63}$ Ibid., p. 97. 
según sus tópicos eurocentristas, que en el caso de América tendrían además plena actualidad a la luz de los intereses neocolonizadores, fundamentalmente económicos, generados en el ocaso de la colonización española. ${ }^{64}$

¿En qué modernidad occidental está pensando entonces Nicol cuando elogia la obra española en América? ¿Reivindicaría, análogamente a Xirau, una singular y supuesta modernidad hispánica, de cariz humanista, frente a la modernidad racio-instrumental y tecno-científica triunfante? Si nos fijamos por una parte en tres artículos que Nicol dedicó tempranamente a la filosofía política del humanismo español, especialmente la de Francisco Suárez, de la que rescata sobre todo su sentido comunitario; ${ }^{65}$ y por otra en la amplia crítica del cientismo moderno desplegado en libros como El porvenir de la filosofía (1972) y La reforma de la filosofía (1980), esta hipótesis no resultaría demasiado aventurada. Sobre el trasfondo de reflexiones como la de Suárez, la colonización española de América se habría distinguido sobre todo por el logro de una "unidad vital y cultural creada por los indios y los españoles conjuntamente desde el primer contacto". ${ }^{66}$ Unidad o "ethos común" 67 que la Independencia - prosigue Nicol- no hará sino consagrar. A partir de entonces, para unos y para otros

[...] comenzó ya entonces algo completamente nuevo, diferencial y propio, en el más severo significado de la palabra; [...] algo que impide en verdad que un hispanoamericano pueda ser considerado extranjero en España. A esa comunidad del espíritu y de la sangre, del verbo encarnado (que fue, marquémoslo bien, para que lo entiendan igualmente los españoles, revelada por la Independencia, y no escindida por ella), la llamaremos hispanidad. ${ }^{68}$

La Independencia supondría en definitiva un momento de reforma, radical, si se quiere, pero no de subversión revolucionaria. Lo nuevo se distingue sobre el trasfondo de una tradición que pervive e incluso se descubre a sí misma bajo una conciencia más libre y reflexiva. Realiza objetivamente una nueva figura dialéctica de lo hispánico, por así decirlo, caracterizada por la "interdependencia". La independencia de América - apunta Nicol en este sentido- "creó justamente la dependencia de España, al producirse la distinción política entre una y otra, y con ella la interdependencia". ${ }^{69}$ En este sentido, la

${ }^{64}$ Ibid., p. 57.

${ }^{65} \mathrm{Cf}$. la nota 6 .

${ }^{66}$ E. Nicol, El problema de la filosofía hispánica, p. 102.

${ }^{67}$ Ibid., p. 95.

${ }^{68}$ Ibid., p. 102.

${ }^{69}$ Ibid., p. 108. 
Independencia sería nada menos que la revelación de la hispanidad, término que pocas décadas antes había acuñado el pensador reaccionario Ramiro de Maeztu en un sentido, si no neo-imperialista, sí tradicionalista, ${ }^{70}$ y que Nicol querrá rescatar o reinventar desde una perspectiva comunitaria -y en definitiva, republicana-, aun cuando soslaya las asimetrías anteriormente apuntadas a propósito de la convivencia colonial: lo hispánico -aclara Nicol- "no es equivalente a lo español", ni se trata tampoco de una suma de partes de aquí y de allá o "un todo" que "es unitario porque las modalidades distintas poseen un elemento o cualidad común". Hispanidad, en este sentido, "es ese elemento común", irreductible al "carácter de lo distintivamente español, que haya dejado su huella indeleble en América", ${ }^{71}$ o a "una renovación o continuidad de la presencia de España en América". ${ }^{72}$ Unidad de lo diverso, por tanto, o "carácter común y distintivo de los hispanoamericanos y los españoles [...] que constituye la unidad solidaria de unos con otros"73 y que subyacerá a la fragmentación inevitable del proceso emancipador, así como a la búsqueda, por parte de la mentalidad emancipada, de su nuevo y auténtico ser.

Esta búsqueda alcanzará además un momento de singular madurez de la mano de una nueva generación de filósofos capaces de desprenderse del sentido "ideológico" que habría acompañado al pensamiento iberoamericano desarrollado en la estela de la Independencia. Korn, Alberini, Vaz Ferreira, Déustua, Farias Brito y Caso, entre otros, no sólo se distinguirían por haber realizado la superación del viejo positivismo decimonónico, sino que además se distinguirían por alumbrar una filosofía in strictu sensu, es decir "como ciencia universal" 74 sin menoscabo de la originalidad de su expresión o "con caracteres a la vez autóctonos y universales". ${ }^{75}$ En las antípodas de la interpretación de Gaos y sobre el trasfondo de un antagonismo palpable entre ambos filósofos, ${ }^{76} \mathrm{Nicol}$ consideraría que la autorreflexión de la que la Independencia es al mismo tiempo causa y efecto, sólo podría consumarse con el ejercicio de un pensar universal y logocéntrico, y no con una radicalización del "inmanentismo" moderno. Esta última interpretación es la que identificaría, no ya a Gaos y a su maestro Ortega, sino también a la de quienes, influidos por el "circunstancialismo" de ambos, han entendido el pensamiento iberoamericano en

${ }^{70}$ Cf. Ramiro de Maeztu, Defensa de la hispanidad. Introd. de Federico Suárez. Madrid, Rialp, 1998.

${ }^{71}$ E. Nicol, El problema de la filosofía hispánica, p. 106.

${ }^{72}$ Ibid., pp. 108 y ss.

${ }^{73}$ Ibid., p. 109.

${ }^{74}$ Ibid., p. 110.

${ }^{75}$ Ibid., p. 112.

${ }^{76}$ Me he aproximado a este antagonismo en "Eduardo Nicol ante el proyecto de un pensamiento en lengua española", op. cit. 
términos de una meditación sobre el propio ser. Para Nicol, este planteamiento se agotaría en una "neo-ideología", ${ }^{77}$ incapaz de superar la condición ideológica de dicho pensamiento a lo largo del siglo XIX, así como el personalismo característico de "la etapa orteguiana" en España, ${ }^{78}$ Ahora bien, esto no significa que Nicol desprecie dicha meditación, la cual acepta -y él mismo ejercita a la largo de El problema de la filosofía hispánica- siempre y cuando discurra en un sentido "ético" más que "existencial", y se asuma su condición "acientífica" o su esterilidad a la hora de pensar rigurosamente los problemas filosóficos, universales por definición. Tampoco significa que Nicol abogue por una uniformidad abstracta y descontextualizada. Significa más bien que lo autóctono y original del pensar constituye un motivo accidental y en ningún caso esencial. Por eso a su juicio lo universal no excluye lo autóctono, pues lo primero se expresa a través de lo segundo sin necesidad "de ocuparse de él temáticamente". ${ }^{79} \mathrm{Al}$ concepto gaosiano de "importación electiva y aportativa" cabría así contraponer el concepto nicoliano de expresión: mientras que el uno pone el acento en la significación autóctona de los problemas universales, el otro lo hace en la universalidad de las expresiones autóctonas. De ahí, en definitiva, dos lecturas de la Independencia con no pocos puntos en común pero al mismo tiempo profundamente disímiles. Si para Gaos significó el alumbramiento de un pensamiento original - "de lengua española", con todo lo que ello implicaba- en Occidente, para Nicol significará más bien la búsqueda de un "ethos" que sólo puede consumarse mediante una reconciliación con el logos occidental; lo cual, lejos de agotarse en una subordinación acrítica a sus tendencias contemporáneas dominantes, tan condicionadas por el anonimato y la uniformidad de la razón instrumental - "razones de fuerza mayor", dirá Nicol en libros posteriores-, habrá de traer consigo una rectificación radical de las mismas o, sencillamente, "una rehumanización del hombre" ${ }^{80}$ La reconciliación con el logos, la fidelidad a sus principios, exigirá así una restitución del mismo frente a sus modernas derivas tecno-científicas y pragmático-instrumentales. Para Nicol, el proyecto de un "ethos" hispánico significado en la Independencia habrá de prolongarse, en última instancia, en un proyecto de "ethos" universal... ¿occidental, en realidad?

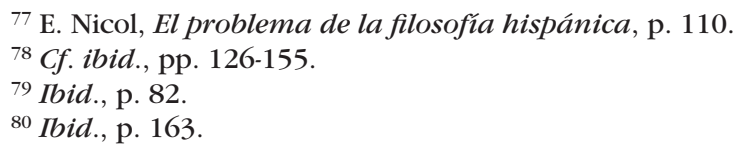

